\title{
Perceptions, beliefs and behaviors of nutritional and supplementary practices in inflammatory bowel disease
}

\author{
Jonathan Sinclair $^{1} \mathbb{D} \cdot$ Stephanie Dillon ${ }^{1} \cdot$ Lindsay Bottoms $^{2}$
}

Received: 2 December 2021 / Accepted: 13 January 2022 / Published online: 3 February 2022

(c) The Author(s) 2022

\begin{abstract}
Purpose To gain insight into the behaviors, perceptions and beliefs of inflammatory bowel disease (IBD) patients nutritional and supplementary practices and also to explore perceptions and behaviors in relation to anti-inflammatory supplementation with specific emphasis on Montmorency tart cherries.

Methods 80 IBD patients completed a 16-item close-ended questionnaire which was divided into three sub-sections: baseline/demographic characteristics, disease characteristics and dietary and supplementary perceptions, beliefs and behaviors. One-sample chi-square goodness of fit tests were used for each question and two-way Pearson chi-square tests of independence were used to undertake bivariate cross-tabulation comparisons to test differences in responses to each question between baseline/demographic variables.

Results The majority of participants $(N=40)$ did not follow a specific dietary pattern or use supplements $(N=56)$. Respondents also predominantly rated that diet can both positively $(N=66)$ and negatively $(N=68)$ influence IBD. In addition, participants rated that supplements can positively influence IBD $(N=65)$ and that lack of scientific evidence was the primary mechanism preventing them from utilizing supplements $(N=34)$. Finally, patients also strongly reported that they would be willing to take Montmorency tart cherry supplementation $(N=73)$.

Conclusions The disconnect between behavior and beliefs in both diet and supplementary practices, indicate that interventions designed to translate beliefs/knowledge into behaviors are warranted. There is also a necessity to undertake well-designed intervention trials examining the efficacy of food supplements, and with patient's willingness to take Montmorency tart cherry, there is a strong rationale for future randomized trials examining the efficacy of tart cherry supplementation in IBD.
\end{abstract}

Keywords Inflammatory bowel disease $\cdot$ Montmorency tart cherry $\cdot$ Ulcerative colitis $\cdot$ Crohn's disease $\cdot$ Diet $\cdot$ Nutrition

\section{Introduction}

The inflammatory bowel diseases (IBD), colitis (UC) and Crohn's disease (CD) exhibit similar disease characteristics. However, with CD, inflammation is present along the lining of the digestive tract, whereas UC mediates inflammation in all aspects of the digestive tract and is primarily observed in the colon $[1,2]$. The global incidence of IBD

Jonathan Sinclair

jksinclair@uclan.ac.uk

1 Research Centre for Applied Sport, Physical Activity and Performance, School of Sport and Health Sciences, Faculty of Allied Health and Wellbeing, University of Central Lancashire, Preston PR1 2HE, Lancashire, UK

2 Centre for Research in Psychology and Sport Sciences, University of Hertfordshire, Hertfordshire, UK is concerningly high, and expanding rapidly in developed nations [3]. Incidence rates as of $1.3 \%$ have been observed in the developed world [4], with the annual fiscal burden of IBD in the US being $>\$ 31.6$ billion [5]. The remitting nature of IBD influences psychological wellbeing, body image and health-related quality of life [6]. IBD reduces social interactions and patients have poorer relationships with friends and family [7]. In addition to health-related quality of life, IBD also diminishes labor force participation, further exacerbating the monetary impact of the disease [8].

The pathogenesis of IBD is multifactorial in nature, with complex interaction between genetics, environmental factors, and the immune system [8]. The predominant environmental factors linked to the etiology of IBD include alterations in diet, antibiotics, other medications, pollution, infection, life stresses, and smoking [9]. Geographical patterns of IBD epidemiology show the highest 
prevalence in developed nations [3], suggesting that Westernized dietary patterns, are connected to IBD etiology [10]. A plethora of nutritional deficiencies are evident in IBD patients owing to chronic malabsorption [11], and thus a range of nutrition therapies have been advocated for the management of IBD [12,13]. There is strong patient interest in the role of diet and nutritional supplementation in IBD [14]; however, the lack of clear scientific evidence aligned to perceived physician indifference leads many patients to utilize non-scientific sources to meet their dietary information requirements [14]. There is a need for more clinical trials for diets in IBD, as well as understanding the perceptions and beliefs of patients.

For most disease symptoms, pharmaceutical intervention is typically adopted [15]. However, medications are often unsuccessful in controlling symptoms [16], and associated with significant side-effects [17]. Additional treatments are increasingly being sought [18] and clinical interest in dietary supplementation has received considerable attention in recent years [19]. Although, randomized interventions are lacking, probiotics have shown promise in both treatment and maintenance of remission in IBD [20]. Similarly, supplementation of vitamin D and Omega-3 has been postulated as potentially efficacious in modulating the clinical symptoms of IBD [21, 22]. However, there is currently a paucity of information regarding behaviors and perceptions of IBD patients' regarding their supplementary practices.

With IBD, excessive reactive oxygen species are generated by macrophages and neutrophils in the intestine [23], in addition to imbalance of oxidative stress and limited capacity of the intestinal antioxidant defence system [24]. Therefore, supplements with antioxidative and antiinflammatory properties have been postulated as therapeutic agents in IBD [25]; although little is known regarding behaviors and beliefs regarding antioxidant supplements. Polyphenols, the most abundant antioxidant in the human diet [26], are effective in animal IBD models [27-29]. Bilberry supplementation has importantly shown significant improvements in biological and self-reported quality of life in human UC patients [25]. Montmorency tart cherries are the richest source of polyphenols [30,31] and may, therefore, have significant potential as natural supplementary agents in IBD patients. Intervention trials using tart cherries for IBD have not yet been considered, and patient perceptions regarding their willingness to take this supplement are currently unknown.

This investigation aims to gain new insight into behaviors, perceptions and beliefs of IBD patient's regarding their nutritional and supplementary practices. Furthermore, this study will also examine IBD patients' perceptions and behaviors in relation to anti-inflammatory supplementation with specific emphasis on Montmorency tart cherries.

\section{Methods}

\section{Ethical considerations}

The study was approved by the institutional review board (HEALTH 0167), and all participants provided consent before taking part in compliance with the declaration of Helsinki.

\section{Study design and participants}

This investigation utilized an observational approach to meet the study aims. Therefore, a self-administered questionnaire hosted via the Jisc online survey platform (Jisc, UK) was anonymously completed by IBD patients. Respondents were recruited through social media (Twitter, Instagram, LinkedIn and Facebook) using accounts belonging to IBD societies, charities and research institutes. Participants were eligible for participation in the study if they were between the ages of 18-65 and diagnosed with either CD, UC or another IBD condition. The survey was available for online completion for 3 months between the dates 23.03.2020 and 23.06.2021. After the period for filling out the questionnaire had ended, responses of 80 participants were received.

\section{Questionnaire}

The questionnaire itself was created after critical appraisal of the scientific literature relating to diet and supplements in IBD patients, allowing pertinent themes for the questionnaire to be identified and questions to be developed. Following this, in accordance with Allan et al. [32] four experts in this scientific area were invited to review the survey to enhance face validity and offered critical comments and improvements prior to formal submission of the study protocol for ethical approval.

Excluding the information page and questions in relation to the provision of informed consent, the questionnaire included 16 close-ended questions which were divided into three sub-sections: baseline/demographic characteristics of the participants, disease characteristics and dietary and supplementary perceptions, beliefs and behaviors. The baseline/demographic questions included gender, age, smoking behavior and alcohol, the disease characteristics section questions included the specific IBD condition that respondents suffered from, their current disease activity and any current medication and the dietary and supplementary perceptions, beliefs and behaviors section questions included specific diet adopted, whether respondents believe that diet can positively influence IBD, whether diet can negatively influence IBD, whether certain foods are avoided, whether 
food supplements are utilized, whether food supplements are beneficial for IBD, factors preventing the utilization of food supplements, the utilization of anti-inflammatory supplements and whether respondents would be willing to utilize Montmorency tart cherry supplementation. The main body of the questionnaire can be found in Supplementary Appendix I. The respondent options available for the dietary, supplemental and medication questions were developed from the current guidelines of Chron's \& Colitis UK and following agreement with the aforementioned experts in this scientific area.

\section{Statistical analyses}

The questionnaire data were entered into SPSS v27 (IBM, SPSS) software and categorical data for each survey question were coded. Proportions for categorical variables following statistical analyses, are expressed as total $(N)$ and also percentages $(\%)$. One-sample chi-square $\left(X^{2}\right)$ goodness of fit tests were used for each question and also the baseline indices to contrast the proportion of participants that had selected each response. In addition, two-way Pearson chi-square tests of independence were used to undertake bivariate cross-tabulation comparisons, specifically to test differences in responses to each question between baseline/ demographic variables; gender, age, disease, disease activity and medication. In the interests of conciseness only tests of independence that displayed statistical significance are presented. As this was the first time that this questionnaire has been utilized, an exploratory factor analysis (EFA) was undertaken to examine the factor structure of the non-baseline/demographic question responses. A principal components model with varimax rotation and eigen values $>1.0$ was used to explore the underlying structure of the questions [33]. Determination of the adequacy of the EFA was undertaken using Bartlett's test and the Kaiser-Meyer-Olkin (KMO) value [34]. Probability values for chi-square tests were calculated by Monte Carlo simulation, and statistical significance for all analyses was accepted as the $P<0.05$ level.

\section{Results}

\section{Exploratory factor analysis}

The KMO statistic was 0.653 , and the result of Bartlett's test was $P=0.002$. The EFA identified three factors, which explained $50.96 \%$ of the variance in the data. Factor 1 involved the questions associated with dietary/supplementary behaviors, i.e., do you adopt a specific diet, do you avoid certain foods, do you use food supplements such as omega-3, probiotics, protein etc. and do you take any supplements that are marketed as anti-inflammatory; Factor 2, the questions associated with disease indices, i.e., disease, disease activity and medication; and Factor 3, the questions associated with dietary/supplementary beliefs/perceptions, i.e., Do you believe diet can influence Inflammatory bowel disease in a positive way, do you believe diet can influence Inflammatory bowel disease in a negative way, do you think food supplements are beneficial for Inflammatory bowel disease, What would prevent you from taking a food supplement and Would you consider taking Montmorency tart cherry concentrate.

\section{Baseline/demographic characteristics}

The baseline/demographic characteristics of the study population are described in Table 1. One-sample chi-square goodness of fit tests showed that there were no significant differences in 'Gender' $\left(X^{2}{ }_{(1)}=0.45, P=0.502\right)$ or 'Disease type' $\left(X^{2}{ }_{(1)}=3.20, P=0.07\right)$. However, there were significant differences in responses for 'Age' $\left(X^{2}{ }_{(8)}=27.78, P=0.001\right)$ with the majority of participants being aged between 21 and 50 years, 'Disease activity' $\left(X^{2}{ }_{(8)}=45.30, P<0.001\right)$ with the majority of participants experiencing mild symptoms and 'Medication' $\left(X^{2}{ }_{(9)}=25.50, P=0.002\right)$ with no-medication, steroids and aminosalicylates being the most commonly selected responses. Finally, there were also significant differences in responses for both 'Smoking behavior' $\left(X^{2}\right.$ ${ }_{(1)}=51.20, P<0.001$ ) with the majority of participants being non-smokers and also 'Alcohol' consumption $\left(X^{2}{ }_{(5)}=91.00\right.$, $P<0.001$ ) which showed that the majority of participants consumed no alcohol or only 1-2 units per week.

\section{Dietary and supplementary perceptions, beliefs and behaviors (one-sample analyses)}

The dietary and supplementary perceptions of the study population are described in Table 2 . There were significant differences in responses for 'Do you adopt a specific diet' $\left(X_{(8)}^{2}=137.14, P<0.001\right)$ which showed that the majority of participants do not follow a specific dietary pattern and also 'Do you avoid certain foods' $\left(X^{2}{ }_{(5)}=31.00, P<0.001\right)$ with the majority of responses being no food groups were avoided, high-fiber and other food conditions.

In addition, there were significant differences in responses for 'Do you believe diet can influence Inflammatory bowel disease in a positive way' $\left(X^{2}{ }_{(2)}=88.23, P<0.001\right)$ and 'Do you believe diet can influence Inflammatory bowel disease in a negative way' $\left(X^{2}{ }_{(2)}=39.20, P<0.001\right)$ with respondents overwhelmingly agreeing that dietary behaviors can have both a positive and negative influence on inflammatory bowel disease.

For the questions in relation to supplementation, there were significant differences in responses for 'Do you use 
Table 1 Baseline/demographic characteristics

\begin{tabular}{|c|c|c|}
\hline Variables & $N$ & $\%$ \\
\hline \multicolumn{3}{|l|}{ Gender } \\
\hline Female & 43 & 53.8 \\
\hline Male & 37 & 46.3 \\
\hline \multicolumn{3}{|l|}{ Age } \\
\hline $18-25$ & 9 & 11.3 \\
\hline $26-30$ & 9 & 11.3 \\
\hline $31-35$ & 15 & 18.8 \\
\hline $36-40$ & 12 & $15.0^{*}$ \\
\hline $41-45$ & 16 & 20.0 \\
\hline $46-50$ & 12 & 15.0 \\
\hline $51-55$ & 5 & 6.3 \\
\hline $56-60$ & 1 & 1.3 \\
\hline $61-65$ & 1 & 1.3 \\
\hline \multicolumn{3}{|l|}{ Disease } \\
\hline UC & 48 & 60.0 \\
\hline $\mathrm{CD}$ & 32 & 40.0 \\
\hline \multicolumn{3}{|l|}{ Disease activity } \\
\hline Remission & 22 & 27.5 \\
\hline Mild & 43 & $53.8^{*}$ \\
\hline Moderate & 13 & 16.3 \\
\hline Severe & 2 & 2.5 \\
\hline \multicolumn{3}{|l|}{ Medication } \\
\hline None & 14 & 17.5 \\
\hline Adalimumab & 6 & 7.5 \\
\hline Azathioprine and mercaptopurine & 8 & 10.0 \\
\hline Golimumab & 1 & 1.3 \\
\hline Infliximab & 6 & $7.5^{*}$ \\
\hline Steroids & 15 & 18.8 \\
\hline Ustekinumab & 4 & 5.0 \\
\hline Vedolizumab & 7 & 8.8 \\
\hline Aminosalicylates (5-ASAs) & 14 & 17.5 \\
\hline Other & 5 & 6.3 \\
\hline \multicolumn{3}{|l|}{ Smoke } \\
\hline Yes & 8 & $10.0^{*}$ \\
\hline No & 72 & 90.0 \\
\hline \multicolumn{3}{|l|}{ Alcohol (units/week) } \\
\hline None & 37 & 46.3 \\
\hline $1-2$ & 28 & 35.0 \\
\hline $3-4$ & 11 & $13.8^{*}$ \\
\hline $5-6$ & 2 & 2.5 \\
\hline $7-9$ & 1 & 1.3 \\
\hline $10+$ & 1 & 1.3 \\
\hline
\end{tabular}

*Significant chi-squared test

food supplements' $\left(X^{2}{ }_{(1)}=12.80, P<0.001\right)$ showing that the majority of participants do not use food supplements, 'Do you think food supplements are beneficial for Inflammatory bowel disease' $\left(X_{(1)}^{2}=7.20, P=0.007\right)$ indicating that respondents feel that supplements are beneficial, 'Do you take any supplements that are marketed as anti-inflammatory' $\left(X^{2}{ }_{(1)}=72.20, P<0.001\right)$ showing that the majority of participants do not use anti-inflammatory supplements and 'What would prevent you from taking a food supplement' $\left(X^{2}{ }_{(5)}=49.60, P<0.001\right)$ indicating that a lack of scientific evidence is the most prominent reason for not IBD patients not taking food supplements. Finally, for 'Would you consider taking Montmorency tart cherry' there was also a significant difference in responses $\left(X^{2}{ }_{(1)}=54.45, P<0.001\right)$ with participants overwhelming indicating that they would be willing to take tart cherry supplementation.

\section{Dietary and supplementary perceptions, beliefs and behaviors (two-way cross-tabulation analyses)}

The dietary and supplementary perceptions of the study population as a function of the baseline/demographic groups are described in Tables 3, 4, 5, 6, 7 .

A significant difference $\left(X^{2}{ }_{(2)}=8.17, P=0.004\right)$ in the responses to 'Do you believe diet can influence Inflammatory bowel disease in a negative way' as a function of 'Gender' was observed, with more females indicating that they not sure as to whether diet negatively influences IBD (Table 3).

There were also significant differences as a function of 'Age' in the responses to 'Do you use food supplements' $\left(X^{2}{ }_{(8)}=14.82, P=0.04\right)$ showing that the $26-50$ was the predominant age range who do not use food supplements but 18-25-year-old group were more likely than not to adopt supplementation and 'Do you take any supplements that are marketed as anti-inflammatory' $\left(X^{2}{ }_{(8)}=41.54, P<0.001\right)$ with $18-50$ being the most common age range for those not using anti-inflammatory supplements (Table 4).

In addition, significant differences were also shown as a function of 'Disease type' in the responses to 'Do you adopt a specific diet' $\left(X_{(8)}^{2}=14.00, P=0.03\right)$ showing that UC patients were more likely to adopt FODMAP and vegetarian diets, 'Do you believe diet can influence Inflammatory bowel disease in a positive way' $\left(X^{2}{ }_{(2)}=5.50, P=0.04\right)$, showing that UC patients were more likely to perceive that diet has a positive influence on IBD and 'Do you think food supplements are beneficial for Inflammatory bowel disease' $\left(X^{2}{ }_{(1)}=3.80, P=0.04\right)$ with UC patients being more likely to perceive that food supplements are beneficial for IBD (Table 5).

In addition, there were also significant differences as a function of 'Disease activity' in the responses to 'Do you believe diet can influence Inflammatory bowel disease in a positive way' $\left(X_{(6)}^{2}=15.46, P=0.02\right)$ showing that patients with mild symptoms were more likely to perceive that diet has a positive influence on IBD and 'Do you think food supplements are beneficial for Inflammatory bowel disease' $\left(X^{2}{ }_{(3)}=10.36, P=0.02\right)$ with patients with mild symptoms 
Table 2 Dietary and supplementary perceptions, beliefs and behaviors

\begin{tabular}{|c|c|c|}
\hline Variables & $N$ & $\%$ \\
\hline \multicolumn{3}{|l|}{ Do you adopt a specific diet? } \\
\hline None & 40 & $50.0^{*}$ \\
\hline FODMAP & 9 & $11.3^{*}$ \\
\hline Anti-inflammatory & 1 & $1.3^{*}$ \\
\hline Mediterranean & 4 & $5.0^{*}$ \\
\hline Vegetarian & 11 & $13.8^{*}$ \\
\hline Vegan & 3 & $3.8^{*}$ \\
\hline Low carbohydrate & 1 & $1.3^{*}$ \\
\hline Palaeolithic & 1 & $1.3^{*}$ \\
\hline Other & 10 & $12.5^{*}$ \\
\hline \multicolumn{3}{|c|}{ Do you believe diet can influence Inflammatory bowel disease in a positive way? } \\
\hline Yes & 66 & $82.5^{*}$ \\
\hline No & 3 & 3.8 \\
\hline Don’t know & 11 & 13.8 \\
\hline \multicolumn{3}{|c|}{ Do you believe diet can influence Inflammatory bowel disease in a negative way? } \\
\hline Yes & 68 & $85.0 *$ \\
\hline No & 0 & 0.0 \\
\hline Don’t know & 12 & 15.0 \\
\hline \multicolumn{3}{|l|}{ Do you avoid certain foods? } \\
\hline No & 20 & 25.0 \\
\hline High fiber & 22 & 27.5 \\
\hline High fat & 15 & $18.8^{*}$ \\
\hline High glycaemic index & 3 & 3.8 \\
\hline Low glycaemic index & 1 & 1.3 \\
\hline Other & 19 & 23.8 \\
\hline \multicolumn{3}{|c|}{ Do you use food supplements such as omega-3, probiotics, protein etc.? } \\
\hline Yes & 24 & $30.0 *$ \\
\hline No & 56 & $70.0 *$ \\
\hline \multicolumn{3}{|c|}{ Do you think food supplements are beneficial for Inflammatory bowel disease? } \\
\hline Yes & 52 & $65.0^{*}$ \\
\hline No & 28 & $35.0^{*}$ \\
\hline \multicolumn{3}{|c|}{ Do you take any supplements that are marketed as anti-inflammatory? } \\
\hline Yes & 2 & $2.5^{*}$ \\
\hline No & 78 & 97.5 \\
\hline \multicolumn{3}{|c|}{ What would prevent you from taking a food supplement? } \\
\hline Fear of increased toilet urgency & 7 & $8.8 *$ \\
\hline Fear of increased abdominal pain & 13 & $16.3 *$ \\
\hline Fear of triggering a flare-up & 17 & 21.3 \\
\hline Taste & 1 & 1.3 \\
\hline Lack of scientific evidence & 34 & 42.5 \\
\hline Other & 8 & 10.0 \\
\hline \multicolumn{3}{|c|}{ Would you consider taking Montmorency tart cherry concentrate? } \\
\hline Yes & 73 & $91.3 *$ \\
\hline No & 7 & $8.8 *$ \\
\hline
\end{tabular}

*Significant chi-squared test being more likely to perceive that food supplements are beneficial for IBD (Table 6).

In addition, there were also significant differences as a function of 'Medication' in the responses to 'Do you believe diet can influence Inflammatory bowel disease in a positive way' $\left(X_{(18)}^{2}=33.02, P=0.02\right)$ showing that patients taking no-medication, steroids and aminosalicylates were more likely to perceive that diet can have a positive influence on 
Table 3 Dietary and supplementary perceptions, beliefs and behaviors-two-way cross-tabulation expressed as a function of Gender

\begin{tabular}{|c|c|c|c|c|c|c|}
\hline \multirow[b]{3}{*}{ Gender } & \multicolumn{6}{|c|}{ Do you believe diet can influence inflammatory bowel disease in a negative way? } \\
\hline & \multicolumn{2}{|c|}{ Yes } & \multicolumn{2}{|c|}{ No } & \multicolumn{2}{|c|}{ Don't' know } \\
\hline & $N$ & $\%$ & $N$ & $\%$ & $N$ & $\%$ \\
\hline Male & 36 & 45.0 & 0 & 0.0 & 1 & 1.3 \\
\hline Female & 32 & 40.0 & 0 & 0.0 & 11 & 13.8 \\
\hline
\end{tabular}

Table 4 Dietary and supplementary perceptions, beliefs and behaviors-two-way cross-tabulation expressed as a function of Age

\begin{tabular}{|c|c|c|c|c|}
\hline \multirow[b]{3}{*}{ Age } & \multicolumn{4}{|c|}{ Do you use food supplements such as omega-3, probiotics, protein, etc.? } \\
\hline & \multicolumn{2}{|c|}{ Yes } & \multicolumn{2}{|l|}{ No } \\
\hline & $N$ & $\%$ & $N$ & $\%$ \\
\hline $18-25$ & 6 & 7.5 & 3 & 3.8 \\
\hline $26-30$ & 4 & 5 & 5 & 6.3 \\
\hline $31-35$ & 5 & 6.3 & 10 & 12.5 \\
\hline $36-40$ & 2 & 2.5 & 10 & 12.5 \\
\hline $41-45$ & 4 & 5 & 12 & 15 \\
\hline $46-50$ & 2 & 2.5 & 10 & 12.5 \\
\hline $51-55$ & 0 & 0 & 5 & 6.3 \\
\hline $56-60$ & 0 & 0 & 1 & 1.3 \\
\hline \multirow[t]{3}{*}{$61-65$} & 1 & 1.3 & 0 & 0 \\
\hline & \multicolumn{4}{|c|}{ Do you take any supplements that are marketed as anti-inflammatory? } \\
\hline & \multicolumn{2}{|c|}{ Yes } & \multicolumn{2}{|l|}{ No } \\
\hline Age & $N$ & $\%$ & $N$ & $\%$ \\
\hline $18-25$ & 0 & 0 & 9 & 11.3 \\
\hline $26-30$ & 0 & 0 & 9 & 11.3 \\
\hline $31-35$ & 0 & 0 & 15 & 18.8 \\
\hline $36-40$ & 0 & 0 & 12 & 15 \\
\hline $41-45$ & 1 & 1.3 & 15 & 18.8 \\
\hline $46-50$ & 0 & 0 & 12 & 15 \\
\hline $51-55$ & 0 & 0 & 5 & 6.3 \\
\hline $56-60$ & 0 & 0 & 1 & 1.3 \\
\hline $61-65$ & 1 & 1.3 & 0 & 0 \\
\hline
\end{tabular}

IBD and 'Do you believe diet can influence Inflammatory bowel disease in a negative way' $\left(X^{2}{ }_{(9)}=17.02, P=0.04\right)$ showing that patients taking no-medication, steroids and aminosalicylates being more likely to perceive that diet can have a positive influence on IBD (Table 7).

\section{Discussion}

This investigation is the first to explore nutritional and supplementary beliefs/practices in IBD patients. In this study, patients habitually did not follow a specific diet, despite overwhelmingly reporting that they believed that diet can both positively and negatively influence IBD symptoms.
Most patients also indicated that they do not consume food supplements, whilst also indicating strongly that they felt that supplements are beneficial for IBD symptoms. Furthermore, lack of scientific evidence was importantly shown to be the primary factor preventing supplement usage, and older patients were less likely to utilize food supplements. Finally, in our IBD population, the overwhelming majority of patients reported a willingness to take Montmorency tart cherry.

Importantly, in agreement with the observations of Vries et al. [35] the current investigation showed that overall, respondents habitually do not follow a specific diet. This was an interesting observation in that respondents also overwhelmingly reported that they believed that diet can both 
Table 5 Dietary and supplementary perceptions, beliefs and behaviors - two-way cross-tabulation expressed as a function of disease modality

\begin{tabular}{|c|c|c|c|c|c|c|c|c|c|c|c|c|c|c|c|c|c|c|}
\hline \multirow[t]{3}{*}{ Disease } & \multicolumn{18}{|c|}{ Do you adopt a specific diet? } \\
\hline & \multicolumn{2}{|c|}{ None } & \multicolumn{2}{|c|}{ FODMAP } & \multicolumn{2}{|c|}{$\begin{array}{l}\text { Anti-inflam- } \\
\text { matory }\end{array}$} & \multicolumn{2}{|c|}{$\begin{array}{l}\text { Mediterra- } \\
\text { nean }\end{array}$} & \multicolumn{2}{|c|}{ Vegetarian } & \multicolumn{2}{|c|}{ Vegan } & \multicolumn{2}{|c|}{$\begin{array}{l}\text { Low carbo- } \\
\text { hydrate }\end{array}$} & \multicolumn{2}{|c|}{ Palaeolithic } & \multicolumn{2}{|c|}{ Other } \\
\hline & $N$ & $\%$ & $N$ & $\%$ & $N$ & $\%$ & $N$ & $\%$ & $N$ & $\%$ & $N$ & $\%$ & $N$ & $\%$ & $N$ & $\%$ & $N$ & $\%$ \\
\hline Crohn's & 17 & 21.3 & 1 & 1.3 & 0 & 0 & 2 & 2.5 & 3 & 3.8 & 0 & 0 & 1 & 1.3 & 1 & 1.3 & 7 & 8.8 \\
\hline $\mathrm{UC}$ & 23 & 28.8 & 8 & 10 & 1 & 1.3 & 2 & 2.5 & 8 & 10 & 3 & 3.8 & 0 & 0 & 0 & 0 & 3 & 3.8 \\
\hline \multirow[t]{3}{*}{ Disease } & & & \multicolumn{16}{|c|}{ Do you believe diet can influence inflammatory bowel disease in a positive way? } \\
\hline & & & \multicolumn{4}{|l|}{ Yes } & & & \multicolumn{4}{|c|}{ No } & & & \multicolumn{4}{|c|}{ Don't' know } \\
\hline & & & $N$ & & & $\%$ & & & $N$ & & & $\%$ & & & $N$ & & & $\%$ \\
\hline Crohn's & & & 24 & & & 30 & & & 3 & & & 3.8 & & & 5 & & & 6.3 \\
\hline UC & & & 42 & & & 52.5 & & & 0 & & & 0 & & & 6 & & & 7.5 \\
\hline \multirow[t]{3}{*}{ Disease } & & & & \multicolumn{15}{|c|}{ Do you think food supplements are beneficial for inflammatory bowel disease? } \\
\hline & & & & \multicolumn{6}{|c|}{ Yes } & & & & \multicolumn{6}{|c|}{ No } \\
\hline & & & & \multicolumn{4}{|l|}{$N$} & \multicolumn{3}{|c|}{$\%$} & & & \multicolumn{2}{|c|}{$N$} & & & & $\%$ \\
\hline Crohn's & & & & \multicolumn{4}{|l|}{17} & \multicolumn{3}{|c|}{21.3} & & & \multicolumn{2}{|c|}{15} & & & & 18.8 \\
\hline $\mathrm{UC}$ & & & & \multicolumn{4}{|l|}{35} & \multicolumn{3}{|c|}{43.8} & & & \multicolumn{2}{|c|}{13} & & & & 16.3 \\
\hline
\end{tabular}

Table 6 Dietary and supplementary perceptions, beliefs and behaviors-two-way cross-tabulation expressed as a function of disease activity

\begin{tabular}{|c|c|c|c|c|c|c|c|c|}
\hline \multirow[t]{3}{*}{ Disease activity } & \multicolumn{8}{|c|}{ Do you believe diet can influence inflammatory bowel disease in a positive way? } \\
\hline & \multicolumn{3}{|c|}{ Yes } & \multicolumn{2}{|c|}{ No } & & \multicolumn{2}{|c|}{ Don't' know } \\
\hline & $N$ & & $\%$ & $N$ & $\%$ & & $N$ & $\%$ \\
\hline Remission & 17 & & 21.3 & 0 & 0 & & 5 & 6.3 \\
\hline Mild & 37 & & 46.3 & 1 & 1.3 & & 5 & 6.3 \\
\hline Moderate & 11 & & 13.8 & 1 & 1.3 & & 1 & 1.3 \\
\hline Severe & 1 & & 1.3 & 1 & 1.3 & & 0 & 0 \\
\hline \multirow[t]{3}{*}{ Disease activity } & & \multicolumn{7}{|c|}{ Do you think food supplements are beneficial for inflammatory bowel disease? } \\
\hline & & \multicolumn{3}{|c|}{ Yes } & & \multicolumn{3}{|l|}{ No } \\
\hline & & \multicolumn{2}{|l|}{$N$} & \multicolumn{2}{|l|}{$\%$} & \multicolumn{2}{|l|}{$N$} & $\%$ \\
\hline Remission & & \multicolumn{2}{|l|}{14} & \multicolumn{2}{|l|}{17.5} & \multicolumn{2}{|l|}{8} & 10 \\
\hline Mild & & \multicolumn{2}{|l|}{33} & \multicolumn{2}{|l|}{41.3} & \multicolumn{2}{|l|}{10} & 12.5 \\
\hline Moderate & & \multicolumn{2}{|l|}{5} & \multicolumn{2}{|l|}{6.3} & \multicolumn{2}{|l|}{8} & 10 \\
\hline Severe & & \multicolumn{2}{|l|}{0} & \multicolumn{2}{|l|}{0} & \multicolumn{2}{|l|}{2} & 2.5 \\
\hline
\end{tabular}

positively and negatively influence IBD symptoms. These observations suggest that from a dietary perspective there is a disconnect between perception and behavior in IBD patients. Although, the weak association between nutrition beliefs and dietary intake is well established [36], as dietary habits play a key role in the complex etiology of IBD [37], this observation indicates that IBD patients may not be adopting appropriate strategies from a nutritional perspective to manage their disease activity. Therefore, it appears based on our observations that interventions designed to translate beliefs/knowledge into nutritional behaviors are warranted and important in IBD patients.

Furthermore, the two-way cross-tabulation analyses showed that UC patients exhibited distinct dietary behaviors and perceptions in relation to $\mathrm{CD}$ in that they were more likely to adopt FODMAP and vegetarian diets and similarly more likely to perceive that diet has a positive influence on IBD symptoms. Malnutrition is a common problem linked to IBD and seems to occur to a greater extent in people with CD (65-75\%) compared to UC 
Table 7 Dietary and supplementary perceptions, beliefs and behaviors-two-way cross-tabulation expressed as a function of medication

\begin{tabular}{|c|c|c|c|c|c|c|}
\hline \multirow[t]{3}{*}{ Medication } & \multicolumn{6}{|c|}{ Do you believe diet can influence inflammatory bowel disease in a positive way? } \\
\hline & \multicolumn{2}{|c|}{ Yes } & \multicolumn{2}{|c|}{ No } & \multicolumn{2}{|c|}{ Don't' know } \\
\hline & $N$ & $\%$ & $N$ & $\%$ & $N$ & $\%$ \\
\hline None & 14 & 17.5 & 0 & 0 & 0 & 0 \\
\hline Adalimumab & 6 & 7.5 & 0 & 0 & 0 & 0 \\
\hline Azathioprine and mercaptopurine & 5 & 6.3 & 2 & 2.5 & 1 & 1.3 \\
\hline Golimumab & 1 & 1.3 & 0 & 0 & 0 & 0 \\
\hline Infliximab & 3 & 3.8 & 0 & 0 & 3 & 3.8 \\
\hline Steroids & 14 & 17.5 & 0 & 0 & 1 & 1.3 \\
\hline Ustekinumab & 2 & 2.5 & 1 & 1.3 & 1 & 1.3 \\
\hline Vedolizumab & 7 & 8.8 & 0 & 0 & 0 & 0 \\
\hline Aminosalicylates (5-ASAs) & 10 & 12.5 & 0 & 0 & 4 & 5 \\
\hline Other & 4 & 5 & 0 & 0 & 1 & 1.3 \\
\hline \multirow[t]{3}{*}{ Medication } & \multicolumn{6}{|c|}{ Do you believe diet can influence Inflammatory bowel disease in a negative way? } \\
\hline & \multicolumn{2}{|c|}{ Yes } & \multicolumn{2}{|c|}{ No } & \multicolumn{2}{|c|}{ Don't' know } \\
\hline & $N$ & $\%$ & $N$ & $\%$ & $N$ & $\%$ \\
\hline None & 14 & 17.5 & 0 & 0 & 0 & 0 \\
\hline Adalimumab & 6 & 7.5 & 0 & 0 & 0 & 0 \\
\hline Azathioprine and mercaptopurine & 5 & 6.3 & 0 & 0 & 3 & 3.8 \\
\hline Golimumab & 1 & 1.3 & 0 & 0 & 0 & 0 \\
\hline Infliximab & 4 & 5 & 0 & 0 & 2 & 2.5 \\
\hline Steroids & 15 & 18.8 & 0 & 0 & 0 & 0 \\
\hline Ustekinumab & 3 & 3.8 & 0 & 0 & 1 & 1.3 \\
\hline Vedolizumab & 6 & 7.5 & 0 & 0 & 1 & 1.3 \\
\hline Aminosalicylates (5-ASAs) & 9 & 11.3 & 0 & 0 & 5 & 6.3 \\
\hline Other & 5 & 6.3 & 0 & 0 & 0 & 0 \\
\hline
\end{tabular}

(18-62\%) [38]. Therefore, patients should be cautious when adopting something like a FODMAP or a vegetarian diet. As malnutrition occurs more in $\mathrm{CD}$, this may be why they are less likely to adopt a diet.

In addition, the findings from this study showed that overall, the predominant food modality that that yielded any useable information that was avoided by respondents was a high-fiber dietary approach. It is likely that this observation relates to the long-held low-residue diet which is often utilized for the management of IBD whereby bowel irritation is minimized by reducing with dietary fiber [39]. However, despite this notion, it has been increasingly recognized that dietary fiber may actually mediate important clinically meaningful benefits in IBD and may help to maintain remission during the course of the disease [40]. As such, it is clear that additional educational developments are required within IBD clinical practice to advocate the benefits of appropriate dietary fiber intake and, thus, improve disease management.

Similar to their dietary behaviors and beliefs, respondents indicated that they do not consume food supplements, whilst also indicating that they felt that supplements are beneficial for IBD symptoms. This observation once again supports the existence of a disconnect between behavior and beliefs in IBD patients concerning their food supplements. This is an interesting observation given the high incidence of nutritional deficiencies in IBD patients [11] and the potential role that supplements have in the management of dietary deficiencies and indeed symptoms in IBD patients [19]. However, the results of this study also importantly confirmed that a lack of scientific evidence was the predominant mechanism preventing patients from taking a dietary supplement. There is currently a paucity of well-designed randomized controlled trials examining the efficacy of food supplements pertinent to the etiology of IBD and also in addressing common nutrition deficiencies in IBD. Therefore, this is an important avenue for future analyses in IBD to provide clinical information to patients and clinicians regarding the potentially important role of food supplements in the avoidance/management of IBD symptoms.

Exploration of the two-way cross-tabulation analyses in relation to supplementary beliefs and behaviors, showed first that UC patients exhibited distinct perceptions in relation to 
supplements compared to $\mathrm{CD}$ in that they were more likely to believe that food supplements are beneficial. In addition, it was also revealed that different age groups showed different supplementary perceptions, in that 18-25-year-old respondents were more likely to consume supplements than older patients. This observation opposes the findings from previous analyses of supplement utilization in the general public which have shown a greater utilization of dietary supplements in older adults [41]. It appears based on the observations that younger IBD patients are more open to the utilization of food supplements. Given the potential benefits of food supplements in IBD patients [19], it is perhaps concerning that older individuals are not taking to manage their disease activity. As lack of scientific evidence is the primary mechanism responsible for preventing respondents from utilizing dietary supplements, further to the above recommendation regarding future randomized controlled trials, it is essential that older patients are involved in the experimental design of these intervention studies.

Finally, the current investigation confirmed overall that respondents did not utilize anti-inflammatory supplements. This observation is perhaps concerning given the inflammatory nature of both $\mathrm{CD}$ and UC, whereby anti-inflammatory supplements may assist with disease management [25]. However, importantly respondents overwhelmingly indicated that they would be willing to take Montmorency tart cherry supplementation. Recent trials have observed improvements in both biological and quality of life parameters with polyphenol rich fruit supplementation in UC patients [25]. Therefore, Montmorency tart cherries have considerable potential owing to their uniquely high polyphenol content [30] as natural supplementary agents to mediate more pronounced clinical improvements IBD patients. The efficacy of Montmorency tart cherry supplementation has not yet been examined in IBD patients; thus, it is clear that such an investigation would be of practical as well as clinical significance. Importantly, the current investigation provides overwhelmingly clear evidence for future randomized trials confirming patient's willingness to take Montmorency tart cherry supplementation.

\section{Conclusion}

The disconnect between behavior and beliefs in relation to patients' diet and supplementary practices, indicate that interventions designed to translate beliefs/knowledge into nutritional behaviors are warranted in IBD patients. With lack of scientific evidence being the primary factor preventing supplement usage and older patients being less likely to utilize food supplements; the is a clear necessity to undertake well-designed randomized controlled trials examining the efficacy of food supplements in IBD and to include older patients in these intervention analyses. Finally, with patient's overwhelming willingness to take Montmorency tart cherry, there is a strong rationale for future randomized trials examining the efficacy of tart cherry supplementation IBD.

Supplementary Information The online version contains supplementary material available at https://doi.org/10.1007/s11332-022-00901-8.

\section{Declarations}

Conflict of interest The authors declare no conflict of interest.

Ethical approval The study was approved by the institutional review board (HEALTH 0167).

Informed consent All participants provided consent before taking part in compliance with the declaration of Helsinki.

Open Access This article is licensed under a Creative Commons Attribution 4.0 International License, which permits use, sharing, adaptation, distribution and reproduction in any medium or format, as long as you give appropriate credit to the original author(s) and the source, provide a link to the Creative Commons licence, and indicate if changes were made. The images or other third party material in this article are included in the article's Creative Commons licence, unless indicated otherwise in a credit line to the material. If material is not included in the article's Creative Commons licence and your intended use is not permitted by statutory regulation or exceeds the permitted use, you will need to obtain permission directly from the copyright holder. To view a copy of this licence, visit http://creativecommons.org/licenses/by/4.0/.

\section{References}

1. Roushan N, Daryani NE, Azizi Z, Pournaghshband H, Niksirat A (2019) Differentiation of Crohn's disease and ulcerative colitis using intestinal wall thickness of the colon: a diagnostic accuracy study of endoscopic ultrasonography. Med J Islam Repub Iran 33:57-62. https://doi.org/10.34171/mjiri.33.57

2. Jarmakiewicz-Czaja S, Piatek D, Filip R (2020) The influence of nutrients on inflammatory bowel diseases. J Nutr Metab 27:2894169. https://doi.org/10.1155/2020/2894169

3. Marion-Letellier R, Savoye G, Ghosh S (2016) IBD: in food we trust. J Crohns Colitis 10(11):1351-1361

4. Burisch J, Munkholm P (2013) Inflammatory bowel disease epidemiology. Curr Opin Gastroenterol 29(4):357-362. https://doi. org/10.1097/MOG.0b013e32836229fb

5. Mehta F (2016) Report: economic implications of inflammatory bowel disease and its management. Am J Manag Care 22:51-60

6. Radford SJ, McGing J, Czuber-Dochan W, Moran G (2021) Systematic review: the impact of inflammatory bowel disease-related fatigue on health-related quality of life. Frontline Gastroenterol 12(1):11-21. https://doi.org/10.1136/flgastro-2019-101355

7. Becker HM, Grigat D, Ghosh S, Kaplan GG, Dieleman L, Wine E, Barkema HW (2015) Living with inflammatory bowel disease: a Crohn's and Colitis Canada survey. Can J Gastroenterol Hepatol 29(2):77-84. https://doi.org/10.1155/2015/815820

8. Bianco AM, Girardelli M, Tommasini A (2015) Genetics of inflammatory bowel disease from multifactorial to monogenic forms. World J Gastroenterol 21(43):12296-12310. https://doi. org/10.3748/wjg.v21.i43.12296

9. Fakhoury M, Negrulj R, Mooranian A, Al-Salami H (2014) Inflammatory bowel disease: clinical aspects and treatments. J Inflamm Res 7:113. https://doi.org/10.2147/JIR.S65979 
10. Rizzello F, Spisni E, Giovanardi E, Imbesi V, Salice M, Alvisi P, Gionchetti P (2019) Implications of the westernized diet in the onset and progression of IBD. Nutrients 11(5):1033-1040. https:// doi.org/10.3390/nu11051033

11. Balestrieri P, Ribolsi M, Guarino MPL, Emerenziani S, Altomare A, Cicala M (2020) Nutritional aspects in inflammatory bowel diseases. Nutrients 12(2):372-380. https://doi.org/10.3390/nu120 20372

12. Green N, Miller T, Suskind D, Lee D (2019) A review of dietary therapy for IBD and a vision for the future. Nutrients 11(5):947955. https://doi.org/10.3390/nu11050947

13. Mahlich J, Matsuoka K, Nakamura Y, Sruamsiri R (2017) The relationship between socio-demographic factors, health status, treatment type, and employment outcome in patients with inflammatory bowel disease in Japan. BMC Public Health 17(1):1-7. https://doi.org/10.1186/s12889-017-4516-0

14. Limdi JK, Aggarwal D, McLaughlin JT (2016) Dietary practices and beliefs in patients with inflammatory bowel disease. Inflamm Bowel Dis 22(1):164-170. https://doi.org/10.1097/MIB.00000 00000000585

15. Chumanevich AA, Chaparala A, Witalison EE, Tashkandi H, Hofseth AB, Lane C, Chumanevich AA (2017) Looking for the best anti-colitis medicine: a comparative analysis of current and prospective compounds. Oncotarget 8(1):228-237. https://doi.org/ 10.18632/oncotarget.13894

16. Hazel K, O'Connor A (2020) Emerging treatments for inflammatory bowel disease. Ther Adv Chronic Dis 11:2040622319899297. https://doi.org/10.1177/2040622319899297

17. Atreya R, Neurath MF, Siegmund B (2020) Personalizing treatment in IBD: hype or reality in 2020? Can we predict response to anti-TNF? Front Med 7:517-525. https://doi.org/10.3389/fmed. 2020.00517

18. Duan L, Cheng S, Li L, Liu Y, Wang D, Liu G (2021) Natural antiinflammatory compounds as drug candidates for inflammatory bowel disease. Front Pharmacol. https://doi.org/10.3389/fphar. 2021.684486

19. Dimidi E, Whelan K (2020) Food supplements and diet as treatment options in irritable bowel syndrome. Neurogastroenterol Motil 32(8):e13951. https://doi.org/10.1111/nmo.13951

20. Silva NO, de Brito BB, da Silva FAF, Santos MLC, de Melo FF (2020) Probiotics in inflammatory bowel disease: does it work? World J Meta Anal 8(2):54-66. https://doi.org/10.13105/wjma. $\mathrm{v} 8 . i 2.54$

21. Fletcher J, Cooper SC, Ghosh S, Hewison M (2019) The role of vitamin $\mathrm{D}$ in inflammatory bowel disease: mechanism to management. Nutrients 11(5):1019. https://doi.org/10.3390/nu11051019

22. Barbalho SM, de Alvares Goulart R, Quesada K, Bechara MD, de Carvalho ADCA (2016) Inflammatory bowel disease: can omega-3 fatty acids really help? Ann Gastroenterol 29(1):37-43

23. Tian T, Wang Z, Zhang J (2017) Pathomechanisms of oxidative stress in inflammatory bowel disease and potential antioxidant therapies. Oxid Med Cell Longev 2017:4535194. https://doi.org/ 10.1155/2017/4535194

24. Bourgonje AR, von Martels JZ, Bulthuis ML, van Londen M, Faber KN, Dijkstra G, van Goor H (2019) Crohn's disease in clinical remission is marked by systemic oxidative stress. Front Physiol 10:499-505. https://doi.org/10.3389/fphys.2019.00499

25. Biedermann L, Mwinyi J, Scharl M, Frei P, Zeitz J, Kullak-Ublick GA, Peschke S (2013) Bilberry ingestion improves disease activity in mild to moderate ulcerative colitis - an open pilot study. J Crohns Colitis 7:271-279

26. Ruskovska T, Maksimova V, Milenkovic D (2020) Polyphenols in human nutrition: from the in vitro antioxidant capacity to the beneficial effects on cardiometabolic health and related interindividual variability - an overview and perspective. Br J Nutr 123(3):241-254. https://doi.org/10.1017/S0007114519002733
27. Wu LH, Xu ZL, Dong D, He SA, Yu H (2011) Protective effect of anthocyanins extract from blueberry on TNBS-induced IBD model of mice. Evid Based Complement Altern Med 23:170-175. https://doi.org/10.1093/ecam/neq040

28. Osman N, Adawi D, Ahrné S, Jeppsson B, Molin G (2008) Probiotics and blueberry attenuate the severity of dextran sulfate sodium (DSS)-induced colitis. Dig Dis Sci 53:2464-2473. https:// doi.org/10.1007/s10620-007-0174-x

29. Montrose DC, Horelik NA, Madigan JP, Stoner GD, Wang LS, Bruno RS, Rosenberg DW (2010) Anti-inflammatory effects of freeze-dried black raspberry powder in ulcerative colitis. Carcinogenesis 32:343-350. https://doi.org/10.1093/carcin/bgq248

30. Kelley DS, Adkins Y, Laugero KD (2018) A review of the health benefits of cherries. Nutrients 10(3):368-375. https://doi.org/10. 3390/nu10030368

31. Sinclair J, Shadwell G, Dillon S, Allan R, Butters B, Bottoms L (2021) Effects of Montmorency tart cherry and blueberry juice on cardiometabolic outcomes in healthy individuals: protocol for a 3-arm placebo randomized controlled trial. Int J Environ Res Public Health 18(18):9759. https://doi.org/10.3390/ijerph1818 9759

32. Allan R, Akin B, Sinclair J, Hurst H, Alexander J, Malone JJ, Ihsan M (2021) Athlete, coach and practitioner knowledge and perceptions of post-exercise cold-water immersion for recovery: a qualitative and quantitative exploration. Sport Sci Health. https:// doi.org/10.1007/s11332-021-00839-3(InPress)

33. Willmer M, Westerberg Jacobson J, Lindberg M (2019) Exploratory and confirmatory factor analysis of the 9-Item Utrecht Work Engagement Scale in a multi-occupational female sample: a crosssectional study. Front Psychol 10:2771. https://doi.org/10.3389/ fpsyg.2019.02771

34. Nievas Soriano BJ, García Duarte S, Fernández Alonso AM, Bonillo Perales A, Parrón Carreño T (2020) Validation of a questionnaire developed to evaluate a pediatric eHealth website for parents. Int J Environ Res Public Health 17(8):2671. https://doi. org/10.3390/ijerph17082671

35. de Vries JH, Dijkhuizen M, Tap P, Witteman BJ (2019) Patient's dietary beliefs and behaviours in inflammatory bowel disease. Dig Dis 37(2):131-139. https://doi.org/10.1159/000494022

36. Spronk I, Kullen C, Burdon C, O'Connor H (2014) Relationship between nutrition knowledge and dietary intake. Br J Nutr 111(10):1713-1726. https://doi.org/10.1017/S00071145140000 87

37. de Castro MM, Corona LP, Pascoal LB, Miyamoto JÉ, IgnacioSouza LM, Ayrizono MDLS, Milanski M (2020) Dietary patterns associated to clinical aspects in crohn's disease patients. Sci Rep 10(1):1-9. https://doi.org/10.1038/s41598-020-64024-1

38. Scaldaferri F, Pizzoferrato M, Lopetuso LR, Musca T, Ingravalle F, Sicignano LL, Gasbarrini A (2017) Nutrition and IBD: malnutrition and/or sarcopenia? A practical guide. Gastroenterol Res Pract. https://doi.org/10.1155/2017/8646495

39. Chiba M, Tsuji T, Nakane K, Komatsu M (2015) High amount of dietary fiber not harmful but favorable for Crohn disease. Perm J 19(1):58-61. https://doi.org/10.7812/TPP/14-124

40. Pituch-Zdanowska A, Banaszkiewicz A, Albrecht P (2015) The role of dietary fibre in inflammatory bowel disease. Przeglad Gastroenterologiczny 10(3):135-140. https://doi.org/10.5114/ pg.2015.52753

41. Gahche JJ, Bailey RL, Potischman N, Dwyer JT (2017) Dietary supplement use was very high among older adults in the United States in 2011-2014. J Nutr 147(10):1968-1976. https://doi.org/ 10.3945/jn.117.255984

Publisher's Note Springer Nature remains neutral with regard to jurisdictional claims in published maps and institutional affiliations. 